\title{
Maternal serum procalcitonin levels in prediction of chorioamnionitis in women with preterm premature rupture of membranes
}

Rabia Zehra Bakar ${ }^{1}$, Nadiye Köroğlu², Lale S. Turkgeldi ${ }^{3}$, Esra N. Tola, Berna Aslan Cetin², Ali Gedikbasi²

\begin{abstract}
${ }^{1}$ Department of Obstetrics and Gynecology, Erbaa State Hospital, Tokat, Turkey 2Department of Obstetrics and Gynecology, University of Health Sciences, Kanuni Sultan Suleyman Training and Research Hospital, Istanbul, Turkey ${ }^{3}$ Bahceci Assisted Reproductive Technology Centre, Istanbul, Turkey ${ }^{4}$ Department of Medicine, Suleyman Demirel University, Isparta, Turkey
\end{abstract}

Submitted: 21 January 2018; Accepted: 6 April 2018; Online publication: 11 July 2019

Arch Med Sci 2021; 17 (3): 694-699

DOI: https://doi.org/10.5114/aoms.2019.86191

Copyright $\odot 2019$ Termedia \& Banach

\section{Abstract}

Introduction: Chorioamnionitis is one of the most important maternal complications in the expectant management of patients with preterm premature rupture of membranes (PPROM). Procalcitonin (proCT), the precursor of the hormone calcitonin, is used to differentiate bacterial infections from non-bacterial ones. The objective of the study was to determine the efficacy of maternal serum procalcitonin levels in the early prediction of chorioamnionitis in women with PPROM.

Material and methods: The study was conducted in 76 pregnant women hospitalized due to PPROM at the maternal-fetal medicine unit of a tertiary center in Istanbul. Patients were followed up with white blood cell (WBC), $C$-reactive protein (CRP) and proCT levels every 2 days. The values of investigated parameters were recorded at the diagnosis of PPROM and at the time of delivery. The maximum values during the follow-up period were also recorded.

Results: Out of the 76 patients with PPROM, 15 (19.73\%) developed clinical chorioamnionitis. No significant difference could be detected in the gravidity, parity, duration of hospitalization and gestational week at diagnosis between those patients who developed clinical chorioamnionitis and those who did not. The WBC at the time of hospital admittance and before delivery, and CRP levels before delivery were statistically higher in the chorioamnionitis group $(p<0.05)$. No difference in the proCT levels could be detected either at the time of hospital admittance or before delivery between the two groups.

Conclusions: Maternal proCT was not found to be predictive of chorioamnionitis. However, since there are reports in the literature that contradict these results, further studies are warranted to determine the true efficacy of proCT in the prediction of clinical chorioamnionitis.

Key words: preterm premature rupture of membranes, chorioamnionitis, procalcitonin, C-reactive protein.

\author{
Corresponding author: \\ Nadiye Köroğlu MD \\ Department of Obstetrics \\ and Gynecology \\ University of Health Sciences \\ Kanuni Sultan Suleyman \\ Training and Research \\ Hospital \\ Istanbul, Turkey \\ E-mail: \\ nadiye_dugan@hotmail.com
}




\section{Introduction}

Preterm premature rupture of membranes (PPROM) is defined as the rupture of fetal membranes before 37 weeks of gestation and is encountered in $2-4 \%$ of singleton pregnancies $[1,2]$. The mechanisms thought to be responsible for PPROM are overdistention of the uterus, ischemia, hemorrhage and most importantly infection and/or inflammation [3]. In the study by Goncalves et al., amniotic cultures of patients with PPROM were found to be positive in $32.4 \%$ of cases. In contrast, microbial invasion was demonstrated in $75 \%$ of women at the time of delivery. This suggests that invasion takes place during the latent phase of labor [4]. Nevertheless, the majority of women with PPROM are asymptomatic at the time of diagnosis [5] and the American College of Obstetricians and Gynecologists recommends expectant management of such patients in the absence of maternal or fetal indications [1]. While the aim of expectant management in patients with PPROM is to reduce severe neonatal complications, the risk of maternal/fetal complications such as fetal distress, cord prolapse, placental abruption, and fetal and maternal infection is increased [6-8]. Chorioamnionitis also increases the risk of preterm birth, respiratory distress syndrome, bronchopulmonary dysplasia, cerebral palsy, periventricular leucomalacia and sepsis [9].

Clinical diagnosis of chorioamnionitis is made in the presence of at least two of the following findings: uterine tenderness, malodorous vaginal discharge, white blood cell (WBC) count of $>20000 / \mathrm{mm}^{3}$, maternal fever $>38^{\circ} \mathrm{C}$, maternal (>120/min) or fetal (> 160/min) tachycardia [10]. A large number of laboratory parameters including C-reactive protein (CRP) have been studied in the maternal serum, amniotic fluid and cervicovaginal samples of patients with PROM for the early diagnosis of chorioamnionitis. However, a laboratory test useful in the prediction of chorioamnionitis has not been found yet.

Procalcitonin (proCT) is an acute phase protein consisting of 116 amino acids and is the precursor of the hormone calcitonin [11]. It has gained acceptance in obstetric practice since it was shown to rise at 3 to $6 \mathrm{~h}$ following bacterial infections and is a sensitive biomarker that differentiates bacterial infections from non-bacterial ones and other inflammatory states [12]. In this study we aimed to determine whether maternal serum proCT levels are useful in the prediction of chorioamnionitis in patients with PPROM.

\section{Material and methods}

This study was conducted in 76 pregnant women admitted with a diagnosis of PPROM to the perinatology unit of the Health Sciences University Kanuni Sultan Suleyman Training and Research
Hospital in Istanbul between January 2016 and November 2016. The approval of the ethics committee was obtained from the Istanbul Bakırkoy Sadi Konuk Training and Research Committee $(2016 / 13)$. All patients were informed in detail about the purpose and nature of the study and their written consent was obtained.

Patients' gestational weeks were determined according to their last menstrual period and first trimester ultrasounds. All patients underwent sterile speculum examinations and obstetric ultrasound evaluation. When amniotic fluid leakage was not evident, an Amnisure test was made to determine the presence of placental $\alpha$-microglobulin-1 (PAMG-1) in cervicovaginal fluid samples. Patients at 24-34 weeks of gestation with a definitive diagnosis of PPROM were included in the study. None of the patients in the study population had any clinical findings or suspicion of chorioamnionitis at the time of hospital admittance.

The inclusion criteria were the absence of a history of preterm labor or premature rupture of membranes in previous pregnancies, a gestational age between 24 and 34 weeks and the absence of signs of chorioamnionitis. Patients presenting with fetal distress, patients who could not be followed up or had to be delivered immediately, those with fetal anomalies and clinical findings of chorioamnionitis were excluded from the study.

The age, gravidity, parity, gestational week at presentation and medical and obstetric histories were recorded. All patients underwent routine evaluation for vital signs and obstetric ultrasound examinations. Blood was drawn for WBC, CRP and proCT evaluations.

During clinical follow-up, patients received prophylactic antibiotherapy (ampicillin-sulbactam $1 \mathrm{~g} 4 \times 1$ i.v. for 2 days, followed by sultamicillin $375 \mathrm{mg} 2 \times 1$ for at least 5 days) and corticosteroids for fetal lung maturation (12 mg betamethasone, twice, $24 \mathrm{~h}$ apart). Patients were followed up with vital signs and laboratory tests during hospitalization. WBC, CRP and proCT tests were repeated every 2 days. The blood drawn for proCT evaluation was centrifuged and analyzed with the Elecsys Brahms proCT kit. The presence of maternal fever $\left(>38^{\circ} \mathrm{C}\right)$ not otherwise explained by other factors, maternal tachycardia (> 100/min), fetal tachycardia (> 160/min), uterine tenderness and malodorous vaginal discharge was determined as clinical chorioamnionitis. The diagnosis of chorioamnionitis was made by clinical signs as described previously.

\section{Statistical analysis}

Data were analyzed using the SPSS 23.0 program. Tests of normality of continuous variables were made using the Kolmogorov-Smirnov and 
Shapiro-Wilk tests. The relationship between continuous variables and presence of chorioamnionitis was evaluated using the Mann-Whitney $U$ test. A value of $p<0.05$ was considered to be statistically significant. To evaluate the predictive effect of investigated markers on the development of chorioamnionitis, multivariate regression analysis was performed.

The optimal cut-off points of investigated markers (CRP, WBC and proCT) were determined by receiver operating characteristic (ROC) analyses. Sensitivity and specificity were also calculated at the best cut-off point. To determine whether investigated markers were independently predic tive for the diagnosis of chorioamnionitis, multilogistic regression analysis was used.

\section{Results}

Among 76 patients with PPROM included in the study, 15 were found to develop chorioamnionitis with a rate of $19.7 \%$. The mean gestational weeks at the time of delivery of the 61 patients who did not develop chorioamnionitis (considered as the control group) and 15 who did develop chorioamnionitis were $32.62 \pm 3.7$ and $30.4 \pm 3.22$, respectively. Although patients with chorioamnionitis were delivered at an earlier gestational week than those without chorioamnionitis, this difference was not statistically significant ( $p=0.054)$ (Table I).

A diagnosis of chorioamnionitis was made in the presence of certain clinical findings. The first blood levels obtained at the time of admittance, the last levels obtained before delivery and the maximum levels during the follow-up period of CRP, proCT and WBC were recorded. The laboratory results of patients with clinical chorioamnionitis and those without chorioamnionitis are compared in Table II.

The pre-delivery (last) CRP levels were statistically significantly higher in the chorioamnionitis group than the non-chorioamnionitis group $(p=0.004)$. In the group of patients who developed chorioamnionitis, the mean CRP level was $59.63 \pm 73.99 \mathrm{mg} / \mathrm{l}$ while the mean CRP level in patients who did not develop chorioamnionitis was as low as $8.87 \pm 9.12 \mathrm{mg} / \mathrm{l}$ (Table II).

WBC levels obtained at the time of admittance and the last parameter prior to delivery were significantly higher in the chorioamnionitis group than the non-chorioamnionitis group ( $p=0.011$, $p<0.0001$, Table II).

ProCT levels obtained at the time of PPROM diagnosis, at the time of delivery and maximum levels during the follow-up period did not differ significantly between chorioamnionitis and non-chorioamnionitis group (Table II).

The ROC analysis of serum WBC and CRP for the diagnosis of chorioamnionitis is shown in Figures 1 and 2 . The areas under the curve for WBC and CRP were 0.714 and 0.744 , respectively. The best cutoffs for serum WBC and CRP were $13.4 \mathrm{G} / \mathrm{l}$ and $9.1 \mathrm{mg} / \mathrm{l}$, respectively. Serum values of WBC greater than this threshold had $80 \%$ sensitivity

Table I. Clinical characteristics of patients with chorioamnionitis and without chorioamnionitis

\begin{tabular}{|lccc|}
\hline Characteristic & $\begin{array}{c}\text { Chorioamnionitis positive } \\
(n=15)\end{array}$ & $\begin{array}{c}\text { Chorioamnionitis negative } \\
(n=61)\end{array}$ & $P$-value \\
\hline Age [years] & $31.07 \pm 6.27$ & $28.88 \pm 6.62$ & 0.3 \\
\hline Gravidity $(n)$ & $3.33 \pm 1.99$ & $3.05 \pm 1.68$ & 0.6 \\
\hline Parity $(n)$ & $1.93 \pm 1.79$ & $1.36 \pm 1.2$ & 0.3 \\
\hline Gestational week at administration & $28.33 \pm 2.97$ & $28.69 \pm 2.97$ & 0.6 \\
\hline Duration of hospitalization [days] & $13.93 \pm 13.43$ & $32.43 \pm 13.98$ & 0.2 \\
\hline Gestational week at delivery & $30.40 \pm 3.22$ & 33.74 & 0.054 \\
\hline
\end{tabular}

Table II. Comparison of laboratory parameters in patients with chorioamnionitis and without chorioamnionitis

\begin{tabular}{|lccc|}
\hline Parameter & $\begin{array}{c}\text { Chorioamnionitis positive } \\
(n=15)\end{array}$ & $\begin{array}{c}\text { Chorioamnionitis negative } \\
(n=61)\end{array}$ & $P$-value \\
\hline First CRP & $15.7 \pm 22.36$ & $6.74 \pm 7.8$ & 0.6 \\
\hline First proCT & $0.05 \pm 0.03$ & $0.04 \pm 0.02$ & 0.051 \\
\hline First WBC & $15.14 \pm 3.21$ & $12.68 \pm 3.62$ & 0.01 \\
\hline Last CRP & $59.63 \pm 73.99$ & $8.87 \pm 9.12$ & 0.004 \\
\hline Last proCT & $0.2 \pm 0.42$ & $0.05 \pm 0.02$ & $<$ \\
\hline Last WBC & $16.87 \pm 4.28$ & $12.56 \pm 3.52$ & 0.0001 \\
\hline Max. proCT & $0.2 \pm 0.4$ & $0.06 \pm 0.02$ & 0.3 \\
\hline
\end{tabular}

Covariates: first $C R P$, first proCT, first $W B C$, last $C R P$, last proCT, last $W B C$, max proCT, $C R P-C$-reactive protein, proCT - procalcitonin, $W B C$ - white blood cells, first - at the time of the diagnosis of preterm premature rupture of membrane, last - at the time of delivery, max. - maximum value of proCT during the follow-up period. 


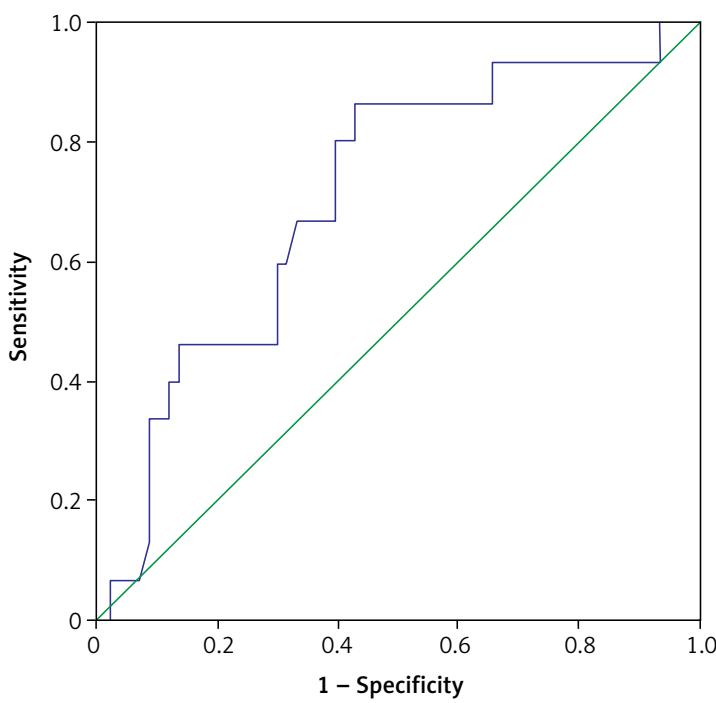

Figure 1. ROC curve for $W B C$ at the time of the diagnosis of PROM for prediction of the development of chorioamnionitis

and $61 \%$ specificity and CRP had $66 \%$ sensitivity and $68 \%$ specificity for the diagnosis of chorioamnionitis. The best cutoff for serum proCT was 0.036 and values greater than this threshold had $53 \%$ sensitivity and $30 \%$ specificity.

We also evaluated the predictive effect of investigated parameters for the development of chorioamnionitis. When first CRP, first proCT, first WBC, last CRP, last proCT, last WBC, and max proCT were taken as covariates, a negative predictive effect of first proCT $(\beta=-82, \mathrm{OR}=0.00001,95 \% \mathrm{Cl}: 0.00001-$ $0.0001), p=0.02)$ and a positive predictive effect of first WBC $(\beta=-0.30, \mathrm{OR}=1.353,95 \% \mathrm{Cl}$ : $1.02-$ $1.78), p=0.03)$ and last $\operatorname{CRP}(\beta=0.06, \mathrm{OR}=1.068$, 95\% Cl: 1.01-1.12, $p=0.01)$ were found. Related data are shown in Table III.

\section{Discussion}

In this study we evaluated the efficacy of maternal serum proCT levels in the prediction of chorioamnionitis, a condition which can develop during the follow-up period of patients with PPROM and lead to severe maternal and fetal complications. The clinical chorioamnionitis rate

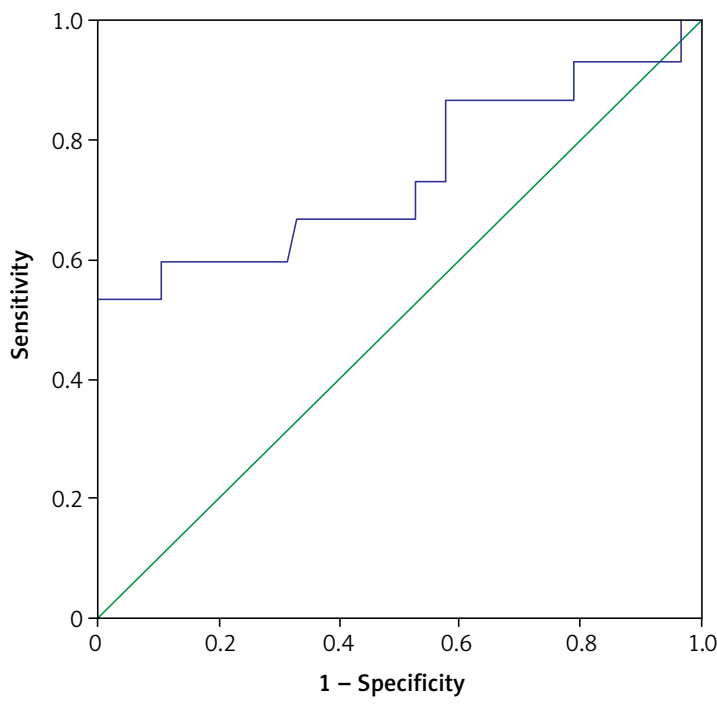

Figure 2. ROC curve for serum CRP levels at the time of delivery for prediction of the development of chorioamnionitis

in this study was $19.7 \%$, in accordance with the rates of $15-25 \%$ reported in the literature [13]. The first and last WBC levels obtained at admittance and just before delivery and the last CRP levels obtained before delivery were significantly higher in patients with chorioamnionitis than patients without chorioamnionitis. However, proCT levels at the time of hospital admittance and the last levels obtained before delivery, and the maximum level of proCT were not statistically significantly different between the two groups.

C-reactive protein is an acute phase protein secreted by the liver in response to inflammation, but it is not specific to infectious conditions. Even though there are contradictory data on its actual usefulness, it is a frequently used clinical parameter in the diagnosis of chorioamnionitis. Fisk et al. reported a significant relationship between increased CRP levels and histological diagnoses of chorioamnionitis. When cut-off values of 30, 35, and $40 \mathrm{mg} / \mathrm{l}$ are used, the predictive value of CRP for chorioamnionitis was reported to be higher. At levels below $20 \mathrm{mg} /$, CRP measurements in patients with infection and those without were

Table III. Predictive effect of proCT, CRP and WBC for the development of chorioamnionitis

\begin{tabular}{|c|c|c|c|c|c|}
\hline \multirow[t]{2}{*}{ Parameter } & \multirow[t]{2}{*}{$\beta$} & \multirow[t]{2}{*}{$P$-value } & \multirow[t]{2}{*}{ OR } & \multicolumn{2}{|c|}{$95 \% \mathrm{Cl}$ for OR } \\
\hline & & & & Lower & Upper \\
\hline First proCT & -82 & 0.02 & 0.00001 & 0.00001 & 0.0001 \\
\hline First WBC & 0.30 & 0.03 & 1.353 & 1.02 & 1.78 \\
\hline Last CRP & 0.06 & 0.01 & 1.068 & 1.01 & 1.12 \\
\hline Constant & -3.89 & 0.07 & 0.02 & & \\
\hline
\end{tabular}

proCT - procalcitonin, WBC - white blood cells, CRP-C-reactive protein, first - at the time of the diagnosis of preterm premature rupture of membrane, last - at the time of delivery. 
found to overlap and the diagnostic value of CRP was found to be limited [14]. Similarly, Nowak et al. used two different cut-off values for CRP (12 vs. $20 \mathrm{mg} / \mathrm{l})$ and reported $12 \mathrm{mg} / \mathrm{l}$ to be a reliable cut-off value when serial samples are obtained [15]. Furthermore, Trochez-Martinez et al. reported in their systematic review that CRP would be predictive of chorioamnionitis above cut-off values of at least $30 \mathrm{mg} / \mathrm{ml}$ if a single blood analysis is to be made, and above $20 \mathrm{mg} / \mathrm{ml}$ if serial blood analyses are to be made [10]. In contrast, many other studies have found CRP to be insufficient in the diagnosis of chorioamnionitis [16-20]. In their study comparing patients with histologically confirmed chorioamnionitis with those without chorioamnionitis Sereepapong et al. reported no difference in CRP levels but a significant difference in maternal leucocyte (WBC) and neutrophil levels when they used cut-off values of $0.5 \mathrm{mg} / \mathrm{dl}, 15 \mathrm{G} / \mathrm{l}$, and $80 \%$ for CRP, leucocyte number and neutrophil percentage, respectively. The sensitivity and specificities were found to be $56 \%$ and $58 \%$ for CRP; $60 \%$ and $63 \%$ for leucocyte number and $62 \%$ and $54 \%$ for neuropil percentage, respectively [19]. In the present study we found the sensitivity and specificities for WBC at the time of hospital admittance to be $46 \%$ and $80.3 \%$ and for WBC obtained before delivery to be $73.3 \%$ and $77.05 \%$, respectively. These findings indicate that chorioamnionitis should be suspected when leucocyte count rises above $15 \mathrm{G} / \mathrm{l}$ even in the absence of clinical findings. When a cut-off value of $5 \mathrm{mg} / \mathrm{l}$ is used, the sensitivity and specificity of CRP for the early diagnosis of chorioamnionitis was found to be $60 \%$ and $47 \%$ in accordance with those reported in the literature [21, 22].

ProCT is a biomarker which increases in response to bacterial infections. However, it does not increase significantly in response to viral or non-infectious inflammations. It is also shown that proCT can be used as a guide both for initiation and discontinuation of antibiotic therapy. Its production is increased in all parenchymal tissues in the presence of bacterial infections and the degree of increase in serum levels is related to the severity of the infection [23]. Torbe et al. reported that proCT from vaginal secretions was a more valuable marker of subclinical infection in patients with PPROM than those with PROM. They also found the sensitivity and specificity of proCT in vaginal secretions to be $25 \%$ and $50 \%$ respectively, when a cut-off value of $2.2 \mathrm{ng} / \mathrm{ml}$ was used for the diagnosis of histologic chorioamnionitis. However, they still found vaginal proCT to be insufficient in the early diagnosis of histologically confirmed chorioamnionitis in patients with PPROM and suspicion of subclinical intrauterine infection [24].
Torbe et al. reported the sensitivity of maternal serum proCT for the early diagnosis of neonatal infection and histological chorioamnionitis to be $53 \%$ and $75 \%$, and the specificity to be $45 \%$ and $45 \%$, respectively, when a threshold value of $1.9 \mathrm{ng} / \mathrm{ml}$ was used [24]. They concluded that maternal serum proCT is insufficient in the diagnosis of histologically confirmed chorioamnionitis and in patients with PPROM with suspected intraamniotic infection [24]. In the current study, sensitivity and specificity for proCT in diagnosis of chorioamnionitis are low when a threshold value of $0.036 \mathrm{ng} / \mathrm{ml}$ is used. However, it should be kept in mind that a low or normal proCT does not exclude bacterial infections especially in localized infections such as chorioamnionitis.

In contrast, Oludag et al. reported the sensitivity and specificity of proCT in the early diagnosis of histological chorioamnionitis as $92.3 \%$ and $68.4 \%$ respectively, when a threshold value of $0.054 \mathrm{ng} / \mathrm{ml}$ was used. Because proCT was found to have a higher specificity than CRP in the early diagnosis of histological chorioamnionitis, they concluded that proCT is more useful during follow-up of patients with PPROM than CRP [22]. Similarly, Kuyumcuoğlu et al. found cervicovaginal liquid proCT, maternal serum CRP, and WBC levels to be significantly higher in patients with chorioamnionitis and suggested that proCT measurements may be useful in the diagnosis of intrauterine infection in patients with PPROM [25].

In conclusion, in the present study the sensitivity, specificity and positive and negative predictive values of proCT for the diagnosis of chorioamnionitis when a threshold value of $0.5 \mathrm{ng} / \mathrm{ml}$ was used were $14.3 \%, 100 \%, 100 \%$ and $83.56 \%$, respectively. The possibility of chorioamnionitis with a proCT value below $0.5 \mathrm{ng} / \mathrm{ml}$ is quite low. The discrepancy between the results of studies reported in the literature is thought to be due to non-standardized proCT measurement techniques that differ from one laboratory to another.

One of the limiting factors of the present study is the small study population. Another limitation is the fact that the correlation between neonatal outcomes and proCT levels has not been evaluated.

\section{Conflict of interest}

The authors declare no conflict of interest.

\section{References}

1. ACOG Committee on Practice Bulletins-Obstetrics. ACOG Practice Bulletin No. 80: Premature rupture of membranes. Clinical management guidelines for obstetrician gynecologists. Obstet Gynecol 2007; 109: 1007-19.

2. Ohlsson A. Treatments of preterm premature rupture of themembranes: a metaanalysis. Am J Obstet Gynecol 1989; 160: 890-906. 
3. Blumenfeld YJ, Lee HC, Gould JB, Langen ES, Jafari A, ELSayed YY. The effect of preterm prematüre rupture of membranes an neonatal mortality rates. Obstet Gynecol 2010; 116: 1381-6.

4. Goncalves LF, Chaiworapongsa T, Romero R. Intrauterine infection and prematurity. Ment Retard Dev Disabil Res Rev 2002; 8: 3-13.

5. Romero R, Quintero R, Oyarzun E, Wu YK, Sabo V, Mazor M, Hobbins JC. Intraamniotic infection and the onset of labor in preterm prematüre rupture of the membranes. Am J Obstet Gynecol 1988; 159: 661-6.

6. Philipson EH, Hoffman DS, Hansen GO, Ingardia CJ. Pretem premature rupture of membranes: experience with latenth periods in excess of seven days. Am J Perinatol 1994; 11: 416-9.

7. Mercer BM, Goldenberg RL, Meis PJ, et al. The Preterm Prediction Study: prediction of preterm premature rupture of membranes through clinical findings and ancillary testing. The National Institue of Child Health and Human Development Maternal-Fetal Medicine Units Network. Am J Obstet Gynecol 2000; 183: 738-45.

8. French JI, McGregor JA. The pathobiology of prematüre rupture of membranes. Semin Perinatol 1996; 20: 344-68.

9. Metcalfe A, Lisonkova S, Sabr Y, Stritzke A, Joseph KS. Neonatal respiratory morbidity following exposure to chorioamnionitis. BMC Pediatr 2017; 17: 128.

10. Trochez-Martinez RD, Smith P, Lamont RF. Use of C-reactive protein as a predictor of chorioamnionitis in preterm prelabor rupture of membranes: a systematicreview. BJOG 2007; 114: 796-801.

11. Perrakis A, Stirkat F, Croner RS, et al. Prognostic and diagnostic value of procalcitonin in the post-transplant setting after liver transplantation. Arch Med Sci 2016; 12: 372-9.

12. Fadel FI, Elshamaa MF, Elghoroury EA, et al. Usefulness of serum procalcitonin as a diagnostic biomarker of infection in children with chronic kidney disease. Arch Med Sci Atheroscler Dis 2016; 1: e23-31.

13. Kenyon S, Boulvain M, Neilson JP. Antibiotics for preterm rupture of membranes. Cochrane Database Syst Rev 2010; 8: CD001058.

14. Fisk N, Fysh J, Child A, Gatenby P, Jeffery H, Bradfield A. Is $\mathrm{C}$-reactive protein reallyuseful in preterm premature rupture of the membranes? Br J Obstet Gynaecol 1987; 94: 1159-64.

15. Nowak M, Oszukowski P, Szpakowski M, Malinowski A, Maciolek-Blewniewska G. Intrauterine infections. I. The role of C-reactive protein, white blood cell count and erythrocyte sedimentation rate in the prediction of chorioamnionitis in cases of premature rupture of membranes. Ginekol Pol 1998; 69: 615-22.

16. Bankowska E, Leibschang J, Pawlowska A. Usefulness of determination of granulocyte elastase plasma level, C-reactive protein and white blood cell count in prediction of intrauterine infection in pregnant women after PPROM. Ginekol Pol 2003; 74: 1037-43.

17. Farb H, Arnesen M, Geistler P, Knox E. C-reactive protein with premature rupture of membranes and premature labor. Obstet Gynecol 1983; 62: 49-51.

18. Kurki T, Teramo K, Ylikorkala O, Paavonen J. C-reactice protein in preterm premature rupture of the membranes. Arch Gynecol Obstet 1990; 247: 31-7.

19. Sereepapong W, Limpongsanurak S, Triratanachat S, Wannakrairot P, Charuruks N, Krailadsiri P. The role of maternal serum C-reactive protein and white blood cell count in the prediction of chorioamnionitis in women with premature rupture of membranes. J Med Assoc Thai 2001; 84: 360-6.
20. Yoon B, Jun J, Park K, Syn H, Gomez R, Romero R. Serum C-reactive protein, white blood cell count, and amniotic fluid white blood cell count in women with preterm premature rupture of membranes. Obstet Gynecol 1996; 88: 1034-40.

21. Torbé A. Maternal plasma procalcitonin concentrations in pregnancy complicated by preterm premature rupture of membranes. Mediators Inflamm 2007; 35: 782-7.

22. Oludag T, Gode F, Caglayan E, Saatli B, Okyay RE, Altunyurt $\mathrm{S}$. Value of maternal procalcitonin levels for predicting subclinical intra-amniotic infection in preterm premature rupture of membranes. J Obstet Gynaecol Res 2014; 40: 954-60.

23. Samsudin I, Vasikaran SD. Clinical utility and measurement of procalcitonin. Clin Biochem Rev 2017; 38: 59-68.

24. Torbe A, Czajka R. Are vaginal fluid procalcitonin levels useful for the prediction of subclinical infection in patients with preterm premature rupture of membranes? J Obstet Gynecol Res 2005; 31: 464-70.

25. Kuyumcuoglu U, Kangal K, Guzel Al, Celik Y. Clinical significance of procalcitonin in cervico-vaginal secretions of women with preterm rupture of membranes. Clin Exp Obstet Gynecol 2010; 37: 319-21. 